\title{
Mechanical and Rheological Properties of Polyurethane Elastomers from Hydroxy-Terminated Polybutadiene and Isophorone Diisocyanate Used as Liners for Composite Propellants
}

\author{
J. Quagliano ${ }^{1, *}$, V. Wittemberg ${ }^{1}$, J. Gonzalez ${ }^{2}$ and A. Bacigalupe ${ }^{2}$ \\ ${ }^{1}$ Instituto de Investigaciones Científicas y Técnicas para la Defensa (CITEDEF), Ave. Juan Bautista de La \\ Salle 4397, B1603ALO, Buenos Aires, Argentina \\ ${ }^{2}$ Centro del Caucho (Rubber Centre), Instituto Nacional de Tecnología Industrial (INTI), Ave Gral. \\ Paz/Migueletes, San Martín, Buenos Aires, Argentina
}

\begin{abstract}
In this contribution, we studied mechanical and rheological properties of liners based on hydroxy terminated polybutadiene (HTPB) loaded with titanium dioxide and cured with isophorone diisocyanate (IPDI) or toluene diisocyanate (TDI). A thixotropic agent (Thixin R) was added, and viscosity was measured as a function of curing time, leading to much lower viscosities and longer pot life values. Mechanical properties (tensile strength and elongation at break) were not significantly affected but viscosity was reduced at all tested concentrations. Loss modulus (G") and storage modulus ( $\left.G^{\prime}\right)$ were measured during cure time at three different temperatures $\left(7,25\right.$ and $\left.60^{\circ} \mathrm{C}\right)$ with IPDI, and at 7 and $25^{\circ} \mathrm{C}$ for TDI. Both curves did not intersect during the cure period studied (120 minutes) for IPDI but did so for TDI at $25^{\circ} \mathrm{C}$ with the formulation having a thixotropic additive. These results suggested that liner formulations will flow if sprayed onto the inner surface of the rocket case before propellant is casted.
\end{abstract}

Keywords: Liner, rheology, applicability, case-bonded, solid rocket motor.

\section{INTRODUCTION}

A liner for composite propellants is basically an elastomeric material applied between the insulation and the propellant to improve interface properties between insulator and propellant and to hold the propellant to the insulated motor case without debonding [1]. The polyurethane-based elastomers on hydroxy-terminated polybutadiene (HTPB) are the polymers of choice when trying to secure a good bond to the propellant rocket motor body and at the same time to protect it from the high temperatures generated by burning the propellant [2]. Viscosity of uncured polyurethane mixtures was reported to increase with the increasing fillers carbon black, silica, aluminum and zirconium dioxide [3]. Excessive viscosity build-up may complicate the application of liners by aspersion.

Liners are usually applied by a spatula or spray on the inner face of the motor tube. In order to facilitate the application onto the inner side of tubes is common practice to dilute with dichloromethane in some proportion [4]. However, another approach which excludes the use of solvents is to add a thixotropic agent to increase the fluence of the liner without

*Address correspondence to this author at the Instituto de Investigaciones Científicas y Técnicas para la Defensa (CITEDEF), Ave. Juan Bautista de La Salle 4397, B1603ALO, Buenos Aires, Argentina; Tel +54 114709 8146; E-mail: jquagliano@citedef.gob.ar affecting its curing properties. Liners are cured with different isocyanates, which differ in its rate of reaction. Aliphatic isocyanates have a slower rate of cure than aromatic isocyanates [5]. Rodić and Petrić [6] investigated the effect of the curing agent on the cure time ("pot life") of different liners compositions and on the properties of these liners for composite propellant formulations. Pot life has been defined as the time necessary for the liner to reach a viscosity of 50,000 cps [7]. In HTPB-based slurry formulations for composite propellants, the flow behaviour was significantly affected by temperature, although these systems have normally a much higher solid filler content than liners [8]. In this respect, fillers have other effects on liner behaviour. When fillers are added to polymeric matrices, normally they increase thermal stability. The properties of the particles themselves (for instance its size, shape and module) can have a significant effect, especially on the mechanical properties, such as specific strain. It was reported that calcium carbonate addition increased the thermal stability of polypropylene (PP) while decreasing yield stress [9]. This is also the case for titanium dioxide in HTPB formulations. However, calcium carbonate was found to have little effect on viscosity build-up in HTPBTDI polyurethane slurries, other than increasing initial viscosity, allowing adding the filler during the polymerization itself [10]. Mahanta and Pathak [11] pointed out that information of change on viscosity during the curing process is critical in modeling the $\mathrm{PU}$ 
flow behaviour. Fillers have a strong influence on thermal and mechanical properties of PUs [12]. Unlike the unfilled PUs, the filled PU slurry showed pseudoplastic behavior, i.e. the shear rate had significant effect on viscosity of the propellant slurry Cured composite solid propellant (CSP) based on HTPB-TDI exhibit nonlinear viscoelastic (NLVE) behavior, that is, their deformation/fracture properties are highly strain-rate and temperature dependent, and only a portion of the applied strain energy is recoverable [13]. Studying liners specifically, Wingborg [14] investigated the effect of polyols, curator and chain extender on the mechanical properties of formulations.

In this contribution, we studied the effect of a fast and slow cure isocyanate and the effect of a thixotropic additive onto the rheological and mechanical properties of HTPB-based liners, with the ultimate and practical objective of determining its applicability by spraying onto metal rocket casings.

\section{MATERIALS AND METHODS}

The HTPB has an average molecular weight of 2,900 Daltons and a polydispersity index of 2.5 (Chinese origin). Toluidine diisocyanate (TDI) was obtained as sample from Petroquímica Rio Tercero (Argentina). The catalyst dibutyl tin laurate (DBTL) and isophorone diisocyanate (IPDI) were purchased from Sigma-Aldrich Corporation, (U.S.A). Commercial titanium dioxide was grounded to a diameter of 10-12 microns. Glyceryl monoricinoleate (MRG) was used as chain extending agent. To formulate the mixtures, all the ingredients were mixed with HTPB under vacuum (4 mm Hg) for 2 hours at $200 \mathrm{rpm}$ with a Coules-type mixer. Finally the isocyanate was added together with DBTL catalyst. To determine viscosity, a "Brookfield" viscometer HBT model was used with different spindles and calculating values in centiPoisse (cps). Rheological measurements were performed at INTI Caucho with an Anton Paar cone-plate rheometer during for 0,5 to 2 hours at the different experimental conditions. Mechanical properties were studied by measuring hardness, tensile strength and elongation to break. Shore A hardness was measured with a DIGIMESS HT-6510 A penetrometer in triplicate on fully cured liner films ( 7 days of curing at ambient temperature) to check that values are within $50-70$ units.

\section{RESULTS}

\subsection{Viscosity Curves}

Viscosity curves with toluidine diisocyanate (TDI) and in with isophorone diisocyanate (IPDI) were obtained. The aliphatic isocyanate IPDI is less reactive than aromatic TDI, so the curing time ("pot life") is longer (120 minutes versus 20 minutes when the mixture cures only with TDI). When the thixotropic agent Thixin R (NL Industries, U.S.) was added, viscosities were reduced, increasing fluence. The results are shown in Figure 1:

It was observed that the curves with IPDI in stoichiometric amount with $\mathrm{OH}$ groups of polyol (PBHT) and chain extended with MRG cured slower than control, as viscosities were lower under all Thixin concentrations experimented. The viscosity of the curing PU system is determined by two factors: (a) the degree of cure, and (b) the temperature.

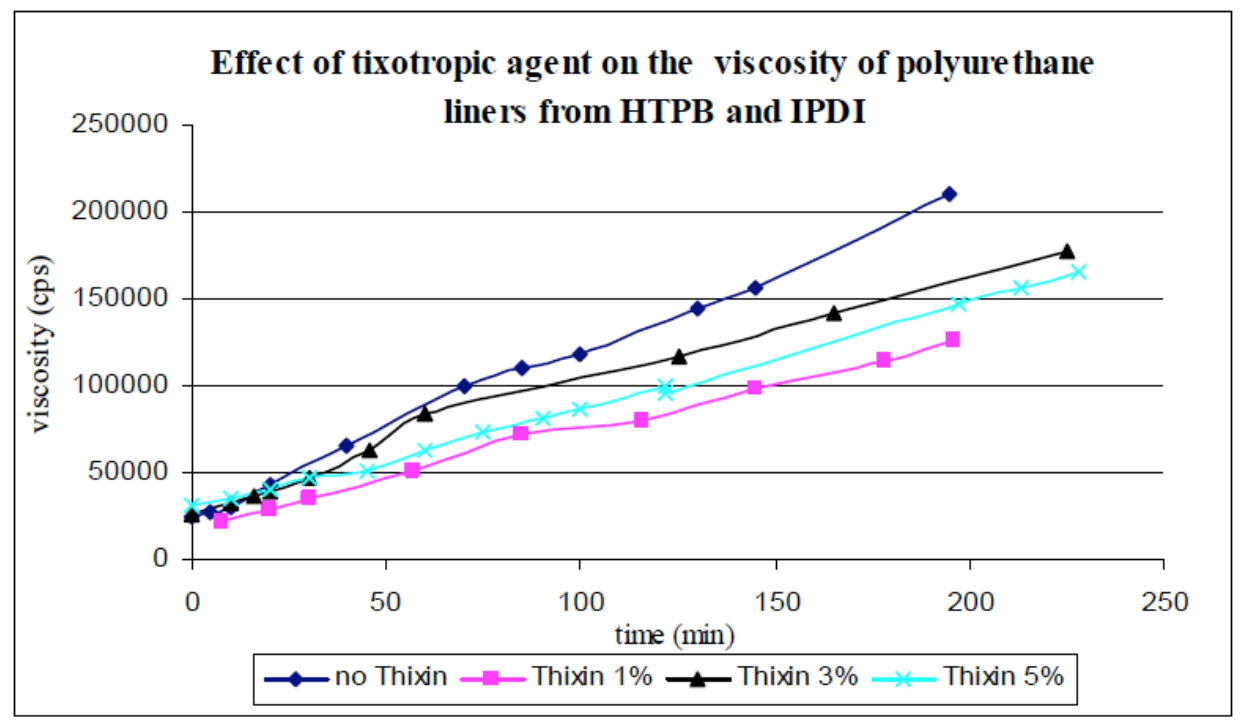

Figure 1: Viscosity curves (cure curves) of liners cured with IPDI with addition of 1, 3 and $5 \%$ of thixotropic agent Thixin R. 
Table 1: Final Mechanical Properties of Slow-Cure Liners after Seven Days of Curing at $20^{\circ} \mathrm{C}$

\begin{tabular}{|c|c|c|}
\hline Sample & Tensile strength (MPa) & Elongation to break (\%) \\
\hline \hline IPDI 7.2\% & 0.53 & 440 \\
\hline 1\% Thixin R & 0.58 & 412 \\
\hline $3 \%$ Thixin R & 0.51 & 350 \\
\hline $5 \%$ Thixin R & 0.54 & 255 \\
\hline
\end{tabular}

\subsection{Mechanical Properties}

Final mechanical properties in liners with Thixin $\mathrm{R}$ at 1,3 and $5 \%$ were measured. Tensile strength and elongation at break were measured after curing at $20^{\circ} \mathrm{C}$ for 7 days. Results are shown in Table 1:

Tensile strength was not significantly affected. Elongation at break on Thixin samples was reduced, although this reduction is not considered to affect liner performance.

Nevertheless, it was reported that $\mathrm{NCO} / \mathrm{OH}$ ratio ( $R$ value) mostly influenced mechanical properties of HTPB as the prepolymer and IPDI as the curing agent [3].

\subsection{Rheological Properties of IPDI and TDI-Cured Liners}

The storage $\left(G^{\prime}\right)$ and loss modulus ( $\left.G^{\prime \prime}\right)$ in viscoelastic materials measure the stored energy, representing G' the elastic portion, and G' the energy dissipated as heat, comprising the viscous portion. Firstly, in our experimental setup, a constant amplitudevariable frequency scan and a constant frequency- variable amplitude scan were made, necessary to set the amplitude and frequency values to be set for studying curing during time. The parameters loss modulus (G") and storage modulus (G') were measured as a function of strain for 120 minutes. In the scans, G" is always greater than G'. This assures that liner formulations will flow if sprayed onto the inner surface of the rocket case before propellant is casted.

Loss (G") and storage (G') modulus curves for the liners cured with $9 \%$ isophorone diisocyanate (IPDI) at three different temperatures $\left(7,25\right.$ and $\left.60^{\circ} \mathrm{C}\right)$ did not intersect during the tested period (120 minutes). In all cases G" is greater than G' indicating that the liner will flow under applied stresses and therefore could be applied by spraying. It was observed that the curves performed at $60^{\circ} \mathrm{C}$ were closer than that at 25 and $7^{\circ} \mathrm{C}$. This confirmed that to accelerate curing is desirable to use a higher temperature, without compromising flow in the case of being applied by spray (as G" was always greater than $\left.\mathrm{G}^{\prime}\right)$.

In general, the level of linear properties such as the storage and loss moduli, G' and G", are always raised with filler addition. However, sometimes a secondary

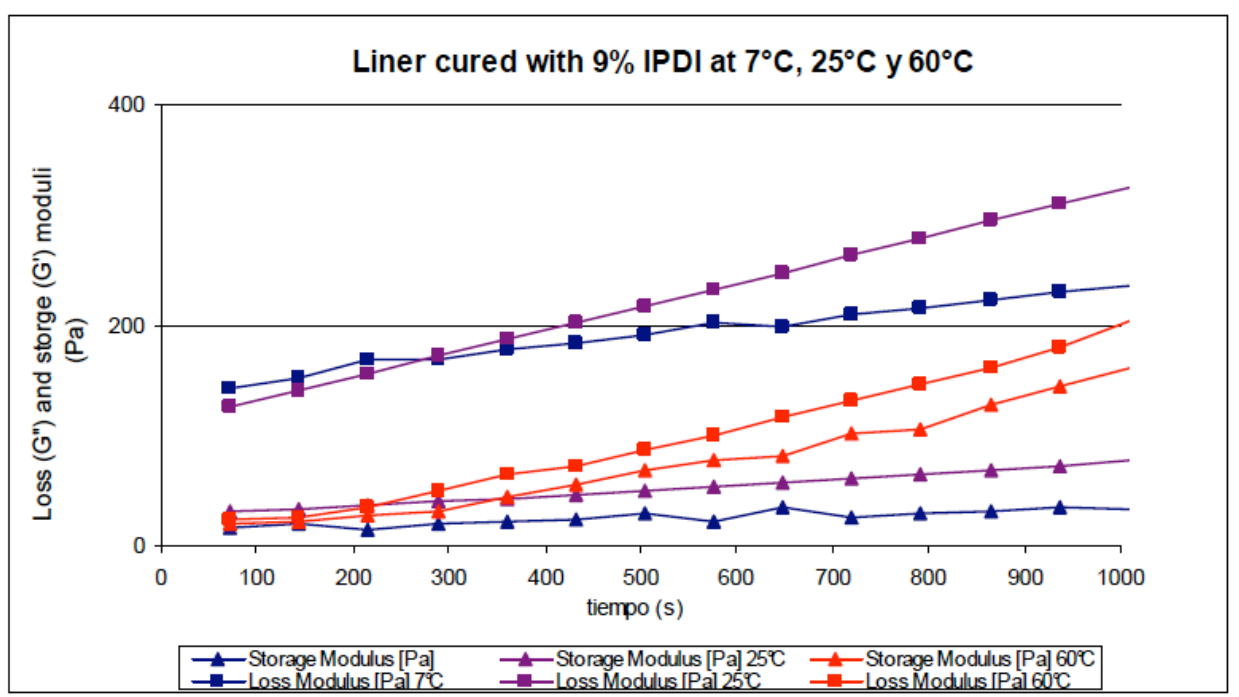

Figure 2: Storage (G') and loss (G") modulus curves of HTPB-based liners cured with $9 \%$ isophorone diisocyanate (IPDI) at three different temperatures. 
mechanism can be seen such as the development of a plateau usually from a pseudo-network set up between flocs or chains of particles [15]. Other authors, while making another type of rheological study (DMA, dynamic mechanical analysis) found similar results but with a liner based on uncatalyzed HTPB cured with IPDI. They observed that G" and G' curves intersected at 30 hours of curing. This time is considered the time for the three-dimensional gel network to form [1]. Beyond the gel time, liner would not flow. Cure time for our liner is much shorter (within 3 hours after curative addition, viscosity reaches around 600,000 cps). Therefore, measurements were done for a shorter period, considering our experimental setup. Dynamic mechanical analysis (DMA) aims at directly measuring the thermo-mechanical properties of the polymer materials, rather than isolated thermal or mechanical properties of uncertain correlation to the overall behaviour [16]. Moreover, other types of techniques are available for rheometry measurements in polymer systems, and provide different kind of information. For example, shear stress-shear rate curves were investigated by the capillary rheometer in high density polyethylene melts [17].

Our experimental results with IPDI showed that loss modulus G" increased during curing time, as viscosity increased as a result of the curing process (Figure 2). It was intriguing to observe that at $7^{\circ} \mathrm{C}$ the complex viscosity curves were lower than at $25^{\circ} \mathrm{C}$ (curves not shown). Indeed, this can be explained considering that two opposing effects are present: the temperature and the curing rate effects. When the temperature rises, the viscosity tends to decrease. Accordingly we would expect the viscosity at $7^{\circ} \mathrm{C}$ to be greater than $25^{\circ} \mathrm{C}$. However, as the temperature increases, the rate of curing also increased and so did the viscosity. In our case, the effect of cure rate prevailed over the temperature effect, which caused the viscosity at $25^{\circ} \mathrm{C}$ to be greater than at $7^{\circ} \mathrm{C}$. Previous reports have shown that the trade-off between temperature and pot life is critical, since increasing the casting temperature decreases the viscosity but increases the rate of curing [18].

\subsection{Liner Formulation with TDI and TDI Plus Thixotropic Agent}

The same experiments were done with a liner formulation cured with TDI alone and with $1 \%$ of the thixotropic agent Thixin $\mathrm{R}$ at 7 and $25^{\circ} \mathrm{C}$.

In the frequency sweeps G" curve was higher than G' curve at $7^{\circ} \mathrm{C}$ but the behavior was the opposite at $25^{\circ} \mathrm{C}$. In the strain sweeps G" curves were higher than

CSD

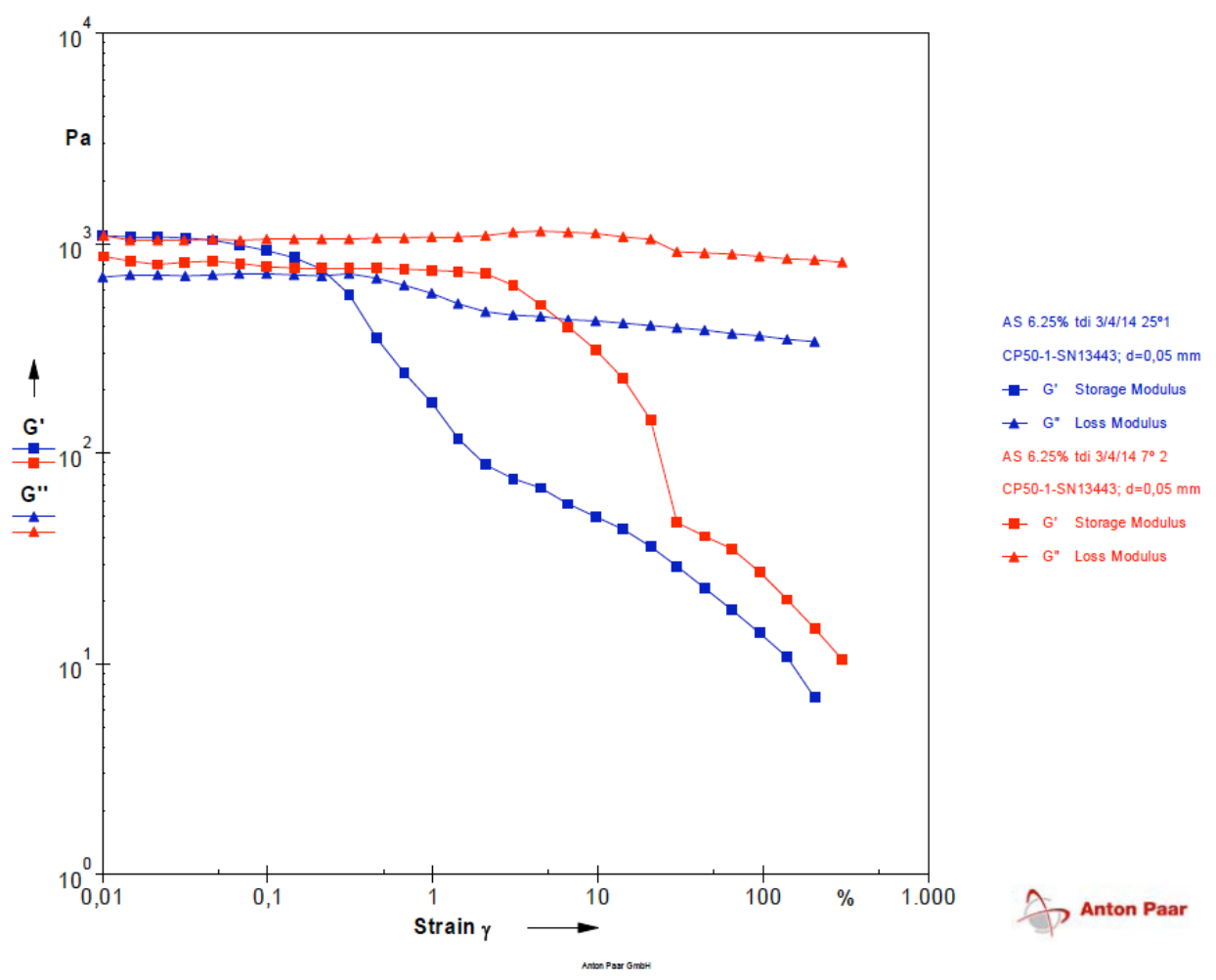

Figure 3: Storage (G') and loss (G") modulus curves of liners cured with TDI at 6,2\% vs. strain. 
G' curves at $7^{\circ} \mathrm{C}$ and they intersected at $0.14 \%$ strain at $25^{\circ} \mathrm{C}$. These results suggested that the liner could be applicated better at $25^{\circ} \mathrm{C}$. The results are shown in Figure 3:

When the thixotropic agent Thixin $\mathrm{R}$ was added at $1 \%(\mathrm{w} / \mathrm{w})$, in the frequency sweeps G" curve intersected $\mathrm{G}^{\prime}$ curve at $151 / \mathrm{s}$ at $7^{\circ} \mathrm{C}$ and $651 / \mathrm{s}$ at $25^{\circ} \mathrm{C}$. In the strain sweeps $\mathrm{G}^{\prime \prime}$ curves intersected $\mathrm{G}^{\prime}$ curves at $0,14 \%$ at $7^{\circ} \mathrm{C}$ and $3 \%$ strain at $25^{\circ} \mathrm{C}$.

As we mentioned above, there are two opposite effects influencing curing: temperature and reaction rate. Increasing temperature has a pronounced effect on curing, accelerating crosslinking and the formation of a gel network. At the same time, increasing temperature diminishes viscosity. However, reaction rate overcame temperature effect, and curing was accelerated at $25^{\circ} \mathrm{C}$. The point of fluence (where $\mathrm{G}^{\prime}$ and $\mathrm{G}^{\prime \prime}$ intersects) was achieved at $25^{\circ} \mathrm{C}$ but not at $7^{\circ} \mathrm{C}$ during the experimental period of study. On the other side, when Thixin $\mathrm{R}$ was added, the fluence point was not altered at $25^{\circ} \mathrm{C}$, but was found at around $2 \%$ strain at $7^{\circ} \mathrm{C}$, as can be seen in Figure 4:

When carring out chemorheological experiments in PU curing systems at different temperatures and different shear rates, it was found that as the cure proceeded, the molecular size increased and so did the cross linking density, which in turn, decreases the mobility of the molecules [10]. In general, for high-solid content HTPB based slurries, at a particular temperature in presence of curing agents, the process of alignment of particles and long-chain HTPB molecules reduces the viscosity of the propellant slurry, whereas the curing reaction increases it because of molecular cross-linking. Initially, the rate of cure is slow; hence, the first process predominates, and later, the second process is controlling [19]. Our results are in agreement with these observations. Respect to the effect of temperature on $G^{\prime}$ and $G^{\prime \prime}$, we observed that they decreased at the higher temperature essayed $\left(25^{\circ} \mathrm{C}\right)$, both with and without Thixin addition. However, temperature dependence of G" was doubled when this tixotrophic additive was added. This suggested that Thixin affects intermolecular forces of HTPB promoting flow at $25^{\circ} \mathrm{C}$ respect to $7^{\circ} \mathrm{C}$, in spite the curing process is accelerated at a higher temperature. This was observed by other authors [20]: both G' and G" decreased with increasing temperature in high-density polyethylene (HDPE)/wood composites. Temperature dependence of the storage modulus (G') of woodplastic composites (WPCs) was obviously higher than

CSD

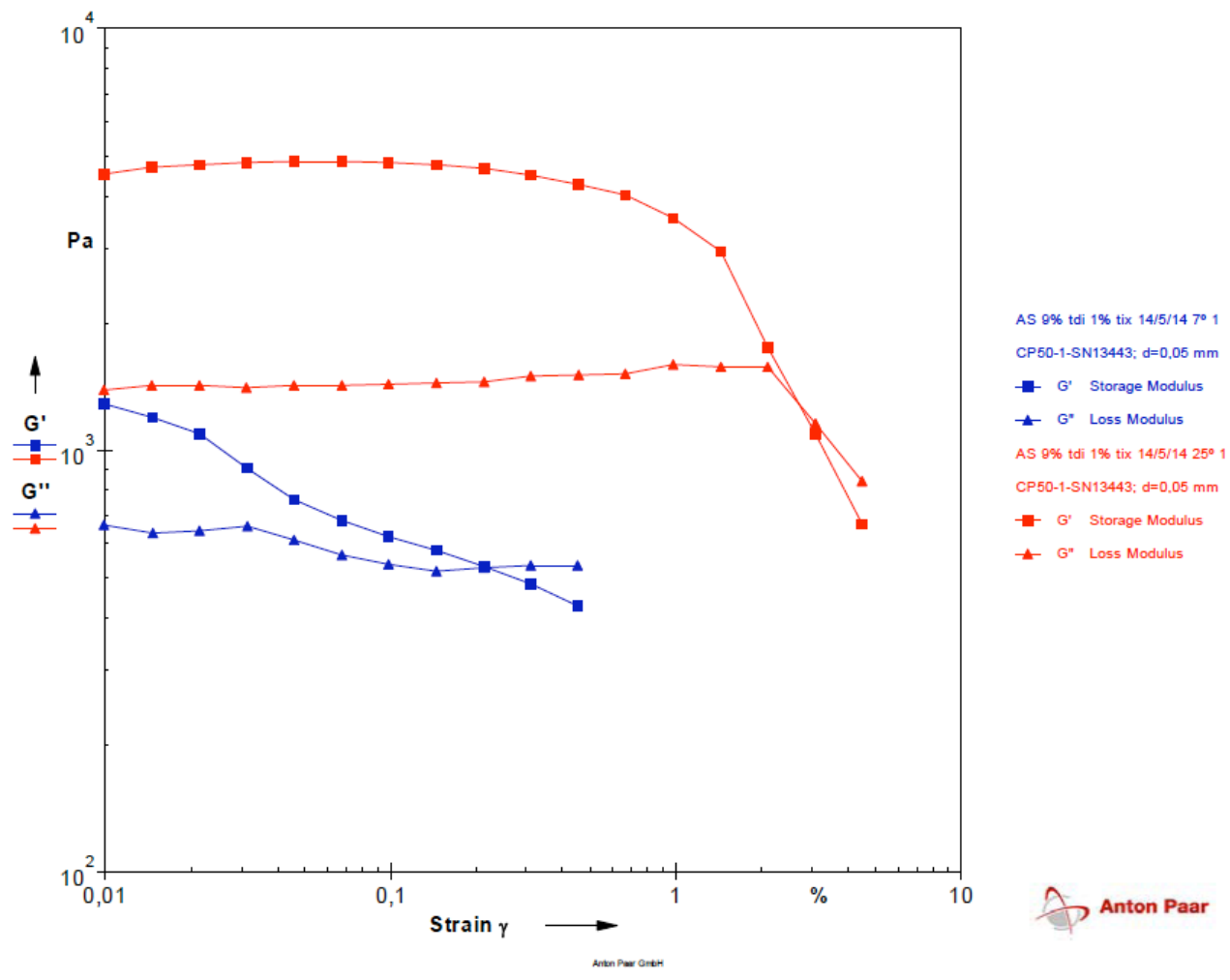

Figure 4: Storage (G') and loss (G") moduli vs. strain curves of liners with TDI and $1 \%$ of thixotropic agent Thixin R (NL Industries, U.S.). 
that of neat HDPE, almost larger by one order of magnitude, which suggested that temperature exerts greater influence on the melt internal intermolecular bonding strength.

From results above, we observed that lower values of both loss and storage modulus (100 to $1,000 \mathrm{~Pa})$ were obtained at $7^{\circ} \mathrm{C}$ with IPDI-cured liners, compared with TDI-cured ones.

\section{CONCLUSIONS}

TDI cured mixtures proved to be of practical value in our technological application as liner for composite propellants. However, IPDI-cured mixtures allowed enough time for pilot plant and production operations to be accomplished. Utilizing this last system at low temperatures $\left(7^{\circ} \mathrm{C}\right)$ resulted in lower values of both loss and storage modulus (100 to $1,000 \mathrm{~Pa})$ than for TDI-cured mixtures, suggesting that application by aspersion will be facilitated. The addition of thixotropic additive lead to much lower viscosity values, without altering final mechanical properties. These results suggested that modification of liner mixtures with this additive could help application of liners without detrimental effect on liner mechanical properties and performance.

\section{REFERENCES}

[1] Ducruet N, Delmotte I, Schrodj G, Stankiewicz F, Desgardin $\mathrm{N}$, Vallat $\mathrm{M}$ and Haidar B. Evaluation of Hydroxyl Terminated Polybutadiene-Isophorone Diisocyanate Gel Formation During Crosslinking Process. J Appl Polym Sci 2012; 1-8.

[2] De Pree D. Liner Technology. Liner Development Methodology Manual. Aerojet Strategic Propulsion Company, Sacramento, California 1982.

[3] Haska S, Bayramli E, Pekel F, Ozcar S. Mechanicalproperties of HTPB-IPDI-based elastomers. J Appl Polym Sci 1997; 1 (64): 2347-354. http://dx.doi.org/10.1002/(SICl)10974628(19970620)64:12<2347::AID-APP9>3.0.CO;2-L

[4] Kakade D, Navale S, Narsinham V. Studies on Interface Properties of Propellant Liner for Case-Bonded Composite Propellants. J Energet Mater 2010; 21(2): 73-85. http://dx.doi.org/10.1080/713845500

[5] Randall D, Lee S. The Polyurethane Book. John Wiley, New York 2002

[6] Rodić V, Petrić V. The effect of curing agents on solid composite rocket propellant characteristics. Sci-Tech Rev 2005; LV: $\mathrm{N}^{0} 1$.
[7] Dias Villar L, Da Silva R, Faria Diniz M, Takahashi M, Rezende $\mathrm{L}$. The role of antioxidante on propellant binder reactivity during termal aging. J Aerosp Technol Manag Sao Jose do Campos 2010; 2(2): 163-168.

[8] Abhay M, Monika G, Devendra PD. Empirical Modeling of Chemoviscosity of Hydroxy Terminated Polybutadiene Based Solid Composite Propellant Slurry. Malay Polym J 2010; 5(1): 1-16.

[9] Alberton J, Martelli S, Soldi V. Obtention and Characterization of Polypropylene, Calcium Carbonate and Poly(ethylene-co-vinyl acetate) Composites. J Res Updat Polym Sci 2012; 1: 5-13.

[10] Reji J, Ravindran P, Neelakantan N and Subramanian N. Viscometry of isothermal polyurethane polymerization. Bull Chem Soc Jpn 1991; 64: 3153-3155. http://dx.doi.org/10.1246/bcsj.64.3153

[11] Mahanta A, Pathak D. HTPB-Polyurethane: A Versatile Fuel Binder for Composite Solid Propellant. In "Polyurethane" Zafar F. and Sharmin E., Eds., Chapter 11, 2012; 229-262.

[12] Benli S, Yilmazer U, Pekel F, Ozkar S. Effect of fillers on thermal and mechanical-properties of polyurethane elastomer. J Appl Polym Sci 1998; 7(68): 1057-1065. http://dx.doi.org/10.1002/(SICl)10974628(19980516)68:7<1057::AID-APP3>3.0.CO;2-E

[13] Vara Prasad DV, Arunachalam V, Ranganathan V. Effect of the Formulation of Ingredients and the Process Parameters on the Fracture Toughness of HTPB Based Composite Solid Propellant. J Energy Chem Eng 2014; 2(3): 94-105.

[14] Wingborg N. Improving the mechanical properties of composite rocket propellants. Stockholm, Sweden. Department of Fibre and Polymer Technology, Royal Institute of Technology 2004.

[15] Barnes HA. A review of the rheology of filled viscoelastic systems. Rheol Rev 2003; 1-36.

[16] Hirschl C, Biebl Rydl M, De Biasi M, Muhleisen W, Neumaier L, Scherf W, Oreski G, Eder G, Chernev B, Schwab W, Kraft $W$. Determining the degree of crosslinking of ethylene vinyl acetate photovoltaic module encapsulants-A comparative study. Solar Energy Mater Solar Cells 2013; 116: 203-218. http://dx.doi.org/10.1016/j.solmat.2013.04.022

[17] Hua-Yong L, Lu-Yao Z, Yong-Bing H, Xian-Jun Z, Xiang X Yan-Wei W. Stick-Slip Transition Behaviour of Two High Density Polyethylene Melts on Capillary Rheometer. J Res Updat Polym Sci 2014; 26-32.

[18] Mahanta AK, Dharmsaktu I, Pattnayak PK. Rheological Behaviour of HTPB-based Composite Propellant: Effect of Temperature and Pot Life on Casting Rate. Defence Sci J 2007; 57(4): 435-442.

http://dx.doi.org/10.14429/dsj.57.1791

[19] Muthiah RM, Krishnamurthy V, Gupta B. Rheology of HTPB Propellant. 1. Effect of Solid Loading, Oxidizer Particle Size, and Aluminum Content. J Appl Polym Sci 1992; 44: 20432052.

http://dx.doi.org/10.1002/app.1992.070441120

[20] Wang X, Yang B, Xia R, Miao J, Qian J, Chen P, Deng S. Lifescience Global Thermal Stability and Rheological Properties of Polyethylene (PE)/ Polyvinylchloride (PVC)/Wood Composites. J Res Updat Polym Sci 2012; 1: 101-109. 